\title{
The Emoji Linguistic Functions on Facebook Interactions among Undergraduate Students at Jadara University in Jordan
}

\author{
Nashat Alshboul \\ School of Arts, Jadara University, Jordan \\ Luqman Rababah \\ Correspondence: Luqman Rababah, School of Arts, Jadara University, Irbid, Jordan \\ P. O. BOX 733, Postal Code 20110, Jordan
}

Received: March 16, 2021

Accepted: March 31, 2021

Published: April 1, 2021

doi:10.5296/jsel.v9i1.18486

URL: https://doi.org/10.5296/jsel.v9i1.18486

\begin{abstract}
This study has made use of a mixed mode design where two instruments are employed namely a corpus based tool and a questionnaire. For three months, the researchers have observed Raseef Jadara Facebook website in order to explore the use of emoji in posts and comments. The results showed that five functions were emerged from the data collected, emotive, conative, phatic, poetic, referential and metalingual. Descriptive statistics were used in conducting a questionnaire in order to show the differences between male and female students in using emoji. The results showed that females prefer using emoji in their chatting or messaging. The researchers suggest further studies to be carried out on the language functions of emoji in other social media platforms Furthermore. It is recommended for other studies to be directed into investigating all language functions.
\end{abstract}

Keywords: Linguistic functions, Emoji, undergraduate students, gender differences, Facebook interaction 


\section{Introduction}

People always need to communicate with each other. They also need to exchange feelings and emotions (Banikalef \& Rababah, 2018). With the advancement of technology, which made the world a small village, the process of communication has become easier than before. Social media platforms are the best proof of this. There are many ways and tools to express these feelings and emotions. One of these tools is the emoji which was first appeared in Japan in the early 1990s and has become widespread these days. Actually emojis are not just symbols; they are the language of human emotions which may convey a strong message. Nowadays, people witness an increasing use of emoji in social media in the world and the fact that they can be connected together to create a sentence with a full meaning raises the question of whether they are creating a new language amongst the new generation, or could change the existing language.

Thus, the present study has investigated Jakobson's linguistic functions of emoji usages through Facebook platform. Moreover, this study explores how emojis are used by Jordanian men and women in online interaction. This study draws its significance from the fact that it is a source of enrichment to the available literature on linguistic studies concerned with corpus analysis and semiotics. It provides an analysis of the distribution of the emoji in the language of chatting as well as the functions used by participants via this platform. This study shows the difference in previous Jordanian studies on emojis or signs in social media especially in Facebook.

The study tries to answer the following research questions:

1. What are the language functions of emoji used by undergraduate student facebookers?

2. How emojis are used by Jordanian men and women in online interaction?

\section{Literature Review}

\subsection{Jakobson's Functions of Language}

Jakobson's model is an effective act of verbal communication that interprets person's ideas and meanings. According to Ramon Jr Serote Medriano (2018, p.5), there are six functions: 


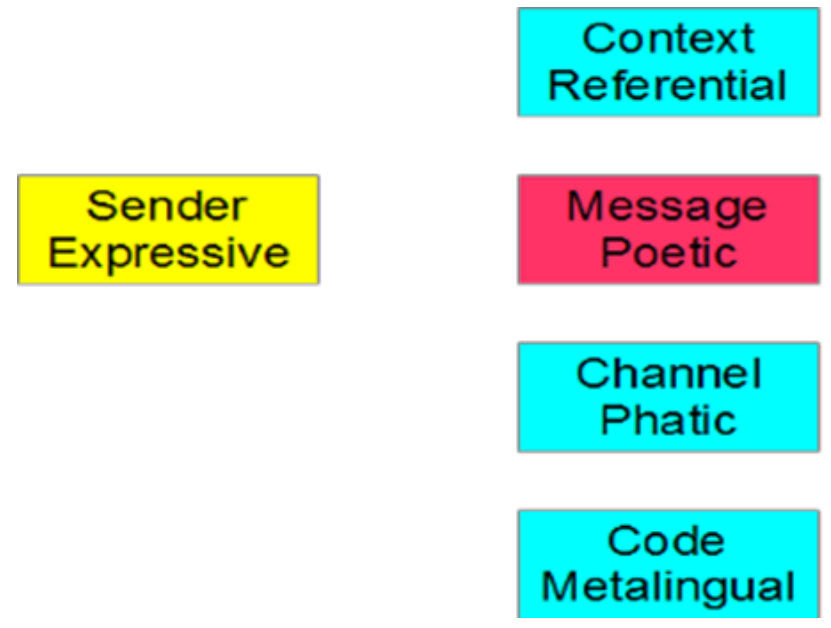

Figure 2.1 Jakobson's Model

1-Emotive Function:bIt relates to the Addresser (sender) and is best exemplified by interjections and other sound changes that do not alter the denotative meaning of an utterance but do add information about the Addresser's (speaker's) internal state).

2-Conative Function : It engages the Addressee (receiver) directly and is best illustrated by vocatives and imperatives).

3-phatic Function : It is language for the sake of interaction and is therefore associated with the Contact/Channel factor. This can be observed in greetings and casual discussions of the weather, particularly with strangers. It also provides the keys to open, maintain, verify or close the communication channel)

4-Poetic Function: It focuses on "the message for its own sake" the code itself, and how it is used and is the operative function in poetry as well as slogans.

5-Referential Function: It corresponds to the factor of Context and describes a situation, object or mental state).

6-Metalingual Function: It is the use of language (what Jakobson calls "Code") to discuss or describe itself). Therefore, with the growing number of Facebook users among the adults and other students, parents and extending beyond friendship, this present study investigates the functions of language in Facebook posting and emojis usage.

\subsection{Related Studies}

Researchers have investigated gender variation levels and linguistic functions of language of emojis users. To start with, Arafah \& Hasyim (2019) investigated the emoji linguistic function in conversations on WhatApp. The study has made use of a questionnaires, and photo documentation (screenshot) of conversations using emojis on WA social media. The results of the study concluded that emojis are part of the grammatical elements of language in communicating on social media. Locally, AL Rousan and Remill (2017) revealed that males and females differ in their use of language in face to face communication and in Computer-mediated Communication. The study of Tribus (2017) discussed the 
communicative functions of language. She concluded that "the elements that affect the production and internalization of language are considerable, but dedicated attention to Jakobson's six communicative functions of language that will allow English language learners to develop a fuller range of communicative ability", (p4). Adebola (2017), carried out a research on semiotics in the Facebook conversations of undergraduate students of Obafemi University in Nigeria. They conclude by suggesting that more smileys and emojis be used by conversationalists

Although many studies have been carried out on language functions such as (Mehawesh, 2013 \& Danesi, 2017), most of the abovementioned studies were not conducted either in the Jordanian context or in social media particularly Facebook. This study, however, focused only on language functions and gender variations while using emoji.

\section{Methods}

This study has used the mixed method approach to investigate gender differences and language functions of emoji at Jadara University in Jordan. The population of the study consists of all Rassef Jadara group on Facebook which has 4000 members in the academic year 2018/2019. All of these members are undergraduate university students whose ages are mostly the same. To collect data, the study has adopted a questionnaire to answer the second research question. The current study has collected adequate comments and posts in order to answer the first research question. To check the validity of the questionnaire used, a team comprising English specialists has been asked to validate the questionnaire. The team included Dr. Sabri Alshboul and Dr. Motasem Almwajeh, provided comments and suggestions upon which modifications were made.

\section{Findings and Discussion}

Question one: What are the language functions of emojis used by undergraduate students Facebookers?

To answer this question the researchers used a corpus based method. After analyzing the data, the following functions emerged.

\subsection{Emotive Function}

Two dialogues had been screenshooted in Raseef Jadara's group among students that show the emotive function while using emojis. The first dialogue is between two female students as shown below:

Afnan : "Hey Ranooshi, where are you? I miss uuuuu

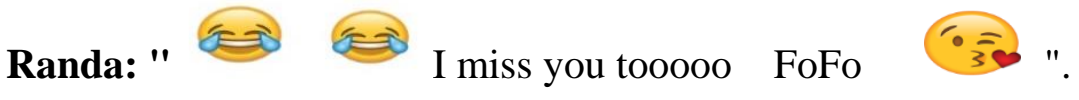


The second dialogue is between male and female students:

Ramzi:" Hi Dalia how are you? You got a nice grade

Mabrook".

\section{Dalia: "Thanks Abu Alroor

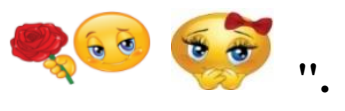

The most common manifestation of the emotive function used between students in this study is the emojis with texts. Simple expressions such as 'WoW' $\bullet$, to express surprise which was used about (26) times. Another way that emotive orientation presents is in the emphatic prolongation of vowels. The statement "big kiss "3e to you" it would more likely be intended and received as emotive because the emoji used is evidence of the speaker's emotional reaction. Even with utterances which might otherwise be classified as belonging to other functions, the infusion of an emotive tone or tint can shift the orientation towards the speaker and imbue the message with new meaning. This may refer to that most of the university students are searching for romantic and emotional relationship especially in this period of their lives and this means that Facebook platform is one of social media used for this purpose.

\subsection{Conative Function}

It is generally assessed in terms of the effects of the message on the behavior of the addressee, for example "Let's get out of the university to have a cup of coffee ! This emoji was used (8) times among students at Jadara University group in their messages. Another example observed by the researchers that shows the conative function in chatting and using emojis between two students is:

Hani: "Be quiet, when the exam starts.

Mofeed:"Ok but I need you to be closed because I didn't study well

Conative function engages the Addressee (receiver) directly and is best illustrated by vocatives and imperatives. The conative function is directed towards the addressee. This function is the purest expression because the sentences were carefully chosen, and it asks people to do something specific.

\subsection{Phatic Function}

This function has been noticed clearly when emojis were used as a nonverbal communication between students' chatting at Raseef Jadara group as shown in table 4.2 below, that displays the indications of emoji's meaning and frequencies. Phatic function denotes or relates to language used for general purposes of social interaction, rather than to convey messages, ask questions, or utterances such as (hello, goodbye etc....). 
Table 4.2 Emojis used as a nonverbal communication

\begin{tabular}{|c|c|c|}
\hline Emoji & Description & Frequency \\
\hline \hline OU & Smile & 12 \\
\hline & Hello, (greeting) & 28 \\
\hline Bye: & Bye & 10 \\
\hline
\end{tabular}

\subsection{Poetic Function}

Many examples have been observed while analyzing students messages. two examples are mentioned as a romantic dialogue among female and male students using emojis with the text:

Example (1):

Raed.J: " I send a nice

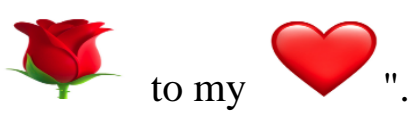

Nana:"

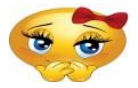

Thanks, I do feel shy".

Example (2):

Sami:" Hey my crazy lady

Nawal:"

It's too early for wedding

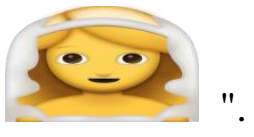

\subsection{Referential Function}

The researchers observed many of emojis used with message's texts among students during last Ramadan and Eid which are two important events in the Muslim world, for example:

"Ramadan Kareem, " , "Ramadan Mubarak

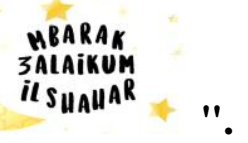

Moh.Safi:" Eid Mubarak my friends

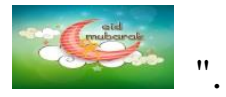

Naief: "

Happy Eid friends". 


\section{Macrothink}

Journal for the Study of English Linguistics

ISSN 2329-7034 2021, Vol. 9, No. 1

Referential function refers to descriptive and contextual information to events and facts that have occurred in all the world that allow someone to express idea. Moreover, it is dominant in an utterance primarily to open a new conversation and this function determines the location of the event.

\subsection{Metalingual Function}

The researchers observed some of emojis that indicate to misunderstanding of the message, as in the dialogue between two students:

Lolo: " Hello Fatin, don't forget bring what you promised (per)

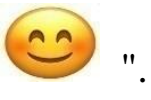

Fatin: "What??? Sorry, I didn't get it".

Lolo:" $\because$ you promised me with that perfume".

Fatin:" huh

Another dialogue also observed by the researchers that displays using emojis as the metalingusal function :

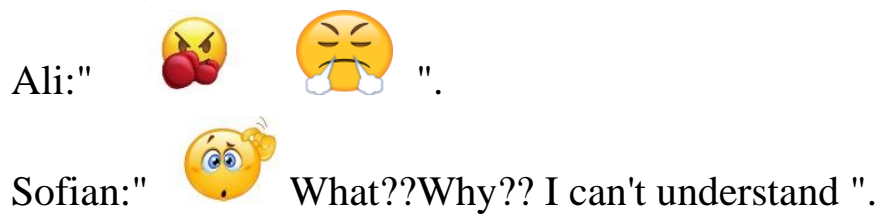

Metalingual function is used when the addresser and the addressee need to use the same code that means same language). Also, it is dominant in an utterance oriented at language itself, which is engaged in the work of negotiating meaning other utterances The metalingual function is used when the addresser and the addressee need to check whether they use the same language that use speaking together or the same code to reach an understanding. Also some of emojis could have ambiguity for the addressee such as angry emojis messages.

Table 4.3 Summary of linguistic functions $(n=50)$

$\begin{array}{lcc}\quad \text { Function } & \text { Frequency } & \text { Percentage } \\ \text { Emotive } & 16 & .32 \\ \text { Conative } & 5 & .1 \\ \text { Referential } & 12 & .24 \\ \text { Poetic } & 6 & .12 \\ \text { Phatic } & 7 & .14 \\ \text { Metalingual } & 4 & .08\end{array}$


As shown in table 4.5 the emotional aspect was the most used, so the emotive function is used more than other functions, the percentage was $(32 \%)$, whereas the minimum function was used is the metalingual function $(8 \%)$.

Question Two: How emojis are used by Jordanian men and women in online interaction?

Descriptive statistics were used in conducting a questionnaire in order to show the differences between male and female students in using emojis in their communication. The gender variation using social media such as Facebook, also a standard deviations of students at Jadara University who use Facebook and due to gender, age and marital status. As such SPSS was used to find any differences according to gender and marital status variables, while one way SPSS was used for age and socioeconomic level as shown in tables $4.4 \& 4.5$ below. The results showed that females prefer using emojis more than texting with others in their chatting or messaging.

Table 4.4 gender variation factor

\begin{tabular}{|c|c|c|c|c|c|}
\hline \multicolumn{6}{|c|}{ Gender } \\
\hline & & Frequency & Percent & $\begin{array}{c}\text { Valid } \\
\text { Percent }\end{array}$ & $\begin{array}{c}\text { Cumulative } \\
\text { Percent }\end{array}$ \\
\hline \multirow[t]{4}{*}{ Valid } & Male & 144 & 32.0 & 32.0 & 32.0 \\
\hline & Female & 306 & 68.0 & 68.0 & 68.0 \\
\hline & Total & 450 & 100.0 & 100.0 & \multirow[b]{2}{*}{100} \\
\hline & & & & & \\
\hline
\end{tabular}

The results also showed that females use emoji more than males in their chatting and messaging (see Table 4.5)

Table 4.5 sending emoji by two genders

Do you like sending emojis

Do you send the same type of emojis to the other more than texting gender? Yes No Total

\begin{tabular}{ll|r|r|r|r}
\hline \multirow{2}{*}{ Yes } & Gender & Male & 6 & 0 & 6 \\
\cline { 2 - 6 } & & Female & 16 & 4 & 20 \\
\cline { 2 - 6 } & Total & & 22 & 4 & 26 \\
\hline \multirow{2}{*}{ No } & Gender & Male & 124 & 14 & 138 \\
\cline { 2 - 6 } & Total & Female & 236 & 50 & 286 \\
\cline { 2 - 6 } & Gender & & 360 & 64 & 424 \\
\hline \multirow{2}{*}{ Total } & Male & 130 & 14 & 144 \\
\cline { 2 - 6 } & Total & & 252 & 54 & 306 \\
\hline
\end{tabular}


Table 4.6 statistics of using emoji to other gender

\begin{tabular}{|c|c|c|c|}
\hline \multicolumn{4}{|c|}{ Statistics } \\
\hline & & Gender & $\begin{array}{l}\text { Do you send the same type of } \\
\text { emojis to the other gender? }\end{array}$ \\
\hline \multirow[t]{2}{*}{$\mathrm{N}$} & Valid & 450 & 450 \\
\hline & Missing & 0 & 0 \\
\hline Mean & & 1.6800 & 1.9422 \\
\hline Std. Deviation & & .46700 & .23358 \\
\hline Variance & & .218 & .055 \\
\hline Range & & 1.00 & 1.00 \\
\hline Minimum & & 1.00 & 1.00 \\
\hline Maximum & & 2.00 & 2.00 \\
\hline Sum & & 756.00 & 874.00 \\
\hline
\end{tabular}

The findings revealed that females use emoji with text messages more than males to express their emotional state as shown in tables above and they use different emojis according to the addressee. A number of studies have been concerned about whether differences in language use by men and women are biologically or socially caused. Generally speaking, the meaning of the emojis differs from one person to another. Such interpretations have turned to differ from one student to another, they are constrained by some independent variables, including the faculties they attend. In almost all languages; some are closer in meaning and function i.e. more synonymous, than others. It is true to say that the use of emojis on social media differs from one person to another and probably from one context to another and the social distance between the sender and the receiver may affect the context. Fourth, given the audience's preferences, there have been at least two main finding. First, the respondents are able to rank their preferences in terms of usage in the given situations; second, they are able to determine the distractor in each context. What this means is that emoji choice is not only conditioned by the context of the situation but also by culture as the choices tend to differ from one country to another.

\section{Conclusion and Recommendations}

In light of the findings given previously, it has been found that the respondents can easily recognize emojis to the ease of their use by both senders and receivers. Moreover, the participants use emojis to maximize the effect on the audience. Furthermore, the participants intentionally use emojis since they are fully aware of the fact that emojis do have different meanings. The majority of the sample can easily interpret the meaning of the emojis if used or sent by others. The interpretations differ from one student to another depending on the age and gender they attend as it is found that gender factor which effect on these emojis usage on both parties (senders and receivers). This may have to do with the nature of the students according to the difference in both gender and age, i.e. students' orientation, way of thinking 
and their readiness for their future can affect their choices according to (Parpala et al., 2010). Given the audience's preferences, the findings have shown at least two main findings. First, in terms of use in the given situations, the respondents are able to rank their preferences; second, they are able to determine the distractor in each context. It is found that "Gender", as a demographic factor, has the most statistically significant effect on the sample in terms of preferences, i.e. students differ in preferring the use of emojis from one faculty to another. The other demographic factors affect the choices of the population sample, but gender is the most dominant one in addition, the findings have shown that emojis do have functions and interpretations and that synonymous interpretations have turned to differ from one student to another for it is found that Faculty, it should be noted here that in light of the given Relevance Theory, the researcher attempted to logically justify the above findings, knowing that in light of the given difference approach and dominance approach, the researcher attempted to justify the results of some previous work such as Chen, Z. et al, (2017). The researchers suggest further studies to be carried out on the language functions of emoji in other social media platforms Furthermore. It is recommended for other studies to be directed into investigating all language functions.

\section{References}

Adebola, O. A. (2017). Semiotics in the Whatsapp conversations of undergraduate students of Obafemi Awolowo University, Ile Ife, Osun State, Nigeria. International Journal of English and Literature, 8(5), 43-62. https://doi.org/10.5897/IJEL2017.1047

Al_Amri, A., \& Rababah, L. (2020). The Effect of Using YouTube on Developing Elementary Students Vocabulary. Education and Linguistics Research, 6(1), 129-139. https://doi.org/10.5296/elr.v6i1.16796

Al-Jarrah, R. S., Dalu, A. M. A., \& Jarrah, M. (2015). A relevance-theoretical account of three Arabic pragmatic operators of concession in a political discourse. Lodz Papers in Pragmatics, 11(1), 51-60.

Almwajeh, M., \& Rababah, L. (2019). There is more to it than meets the eye: an intercultural study of religious speech acts between Jordanian and American students. International Journal of Linguistics, 11(1), 34-45.

Almwajeh, M., \& Rababah, L. (2018). Literature is the best tool of awaking moral understanding and evaluation: Wendell Berry's The Long-Legged House. AWEJ for Translation \& Literary Studies, 2(2), 69-80.

Alshehab, M., \& Rababah, L (2020). Lexical Legal Problems committed by translation students When translating English legal sentences into Arabic at Jadara University in Jordan. The Asian EFL Journal, 24(3), 120-134. (Scopus)

Arafah, B., \& Hasyim, M. (2019). Linguistic functions of emoji in social media communication. Opcion, 35(24), 558-574. 


\section{Mll Macrothink}

Journal for the Study of English Linguistics

ISSN 2329-7034

2021, Vol. 9, No. 1

Banikalef, A., \& Rababah, L. (2018). Gender differences and emotional expressiveness on Facebook: An analysis of prosodic features among Jordanian Facebookers. Studies in Linguistics and Literature, 2(3), 180-184.

Chen, Z., Lu, X., Ai, W., Li, H., Mei, Q., \& Liu, X. (2018, April). Through a gender lens: Learning usage patterns of emojis from large-scale android users. In Proceedings of the 2018 World Wide Web Conference (pp. 763-772).

Dos Reis, J. C., Bonacin, R., Hornung, H. H., \& Baranauskas, M. C. C. (2018). Intenticons: Participatory selection of emoticons for communication of intentions. Computers in Human Behavior, 85, 146-162.

Danesi, M. (2017). The Semiotics of Emoji: The Rise of Visual Language in the age of the Internet. London: Bloomsbury Publishing, Plc. UK

Fischer, A., \& LaFrance, M. (2015). What drives the smile and the tear: Why women are more emotionally expressive than men. Emotion Review, 7(1), 22-29.

Hirsto, L., \& Tirri, K. (2009). Motivational approaches to the study of theology in relation to spirituality. Journal of Empirical Theology, 22(1), 88-102

Jdaitawi, M., Ishak. N., Taamneh, M., Gharaibeh, M., \& Rababah, L. (2011). The Effectiveness of Emotional Intelligence Training Program on Social and Academic Adjustment among First Year University Students. International Journal of Business and Social Science, 2(24). 251-258.

Mikkonen, J., \& Ruohoniemi, M. (2011). How do veterinary students' motivation and study practices relate to academic success?. Journal of veterinary medical education, 38(3), 298-304.

Rababah, L. (2020). Speech act analysis of WhatsApp statuses used By Jordanians. Review of European Studies, 12(2), 28-32.

Rababah, L. (2020). Jadara University Students' Attitudes towards the Use of Microsoft Teams in Learning English as a Foreign Language. Studies in Linguistics and Literature, 4(4), 59-64.

Rababah, L. (2018). An adapted version of Torrance Test of Creative Thinking (TTCT) In EFL/ESL writing: A rubric scoring and a review of studies. International Journal of English and Education (IJEE), 7(2), 128-136.

Rababah, I., \& Rababah, L. (2017). Investigating Arabic to Speakers of Other Languages (ASOL) Lecturers' Attitudes towards Utilizing Flipped Classroom Instruction (FCI): A Qualitative Study at Jordanian Public Universities. International Educational studies, 10(7), 80-91.

Rababah, L., \& Bani Melhem, N. (2015). Investigation into Strategies of Creativity in EFL Writing in Jordan. Journal of Literature, Languages and Linguistics, 5(23), 14-25. Retrieved from http://www.iiste.org/Journals/index.php/JLLL/article/view/17777/18153 
Rababah, L., Halim, A., Jdaitawi, M., \& Bani Melhem, N. (2013). The level of creativity in English writing among Jordanian secondary school students. Arts and Design Studies, 10, 25-29. Retrieved from www.iiste.org/Journals/index.php/ADS/article/download/6094/6226

Rababah, I., \& Rababah, L. (2018). The actual use of brainstorming strategy among teachers of Arabic for speakers of other languages in writing classes. International Journal of English Linguistics, 9(1), 133-143. https://doi.org/10.5539/ijel.v9n1p15

Rababah, L., Alshehab, M., \& Bani Melhem, N. (2018). Exploring the Factors that Hinder Jordanian Students in Developing Creativity in EFL Writing. International Journal of English and Education (IJEE), 7(3), 161-170.

Recuero, R. (2015). Social media and symbolic violence. Social media+ society, 1(1), https://doi.org/2056305115580332

Shaari, A. H., \& Bataineh, K. B. (2015). Netspeak and a Breach of Formality: Informalization and Fossilization of Errors in Writing among ESL and EFL Learners. International Journal for Cross-Disciplinary Subjects in Education (IJCDSE), 6(2).

Simon, R. W., \& Nath, L. E. (2004). Gender and emotion in the United States: Do men and women differ in self-reports of feelings and expressive behavior?. American journal of sociology, 109(5), 1137-1176.

\section{Copyright Disclaimer}

Copyright for this article is retained by the author(s), with first publication rights granted to the journal.

This is an open-access article distributed under the terms and conditions of the Creative Commons Attribution license (http://creativecommons.org/licenses/by/3.0/). 